\title{
Hepatitis B virus reactivation risk varies with different chemotherapy regimens commonly used in solid tumours
}

\author{
W H Y Ling ${ }^{1}$, P P Soe ${ }^{1}$, A S L Pang ${ }^{1}$ and S-C Lee L $^{*}$ \\ ${ }^{1}$ Department of Haematology-Oncology, National University Cancer Institute, National University Health System, \\ Singapore, Singapore
}

Background: Hepatitis B virus (HBV) reactivation may occur with chemotherapy and has significant morbidity and mortality. The United States Centre for Disease Control and Prevention recommends pre-chemotherapy hepatitis B screening for all cancer patients, while the American Society of Clinical Oncology finds that there is insufficient evidence currently to support such a recommendation. Apart from anthracyclines, HBV reactivation rates from other commonly used chemotherapy regimens in solid tumours are not well described.

Methods: We compared HBV reactivation risk in patients receiving several commonly used chemotherapy regimens for solid tumours associated with different immunosuppression risk at a tertiary cancer centre in an HBV endemic region.

Results: A total of 1149 patients were identified, including 434, 196, 245 and 274, respectively, who received doxorubicin-based, oxaliplatin- or irinotecan-based, carboplatin/gemcitabine, and capecitabine chemotherapy. HBV screening rate was $39 \%$ overall. Thirty out of 448 (7\%) screened patients were HBsAg positive and 28 out of 30 received prophylactic antiviral therapy with no reactivation. Three out of 1149 patients overall (0.3\%) developed HBV reactivation, all from the unscreened doxorubicin group (3 out of $214,1.4 \%$ ). No unscreened patients ( 0 out of 487 ) in the other three treatment groups developed reactivation $(P<0.001)$.

Conclusion: Not all chemotherapy regimens result in HBV reactivation. Routine hepatitis B screening for low- or moderate-risk regimens may not be warranted.

Chronic hepatitis B infection is a global public health issue with $>350$ million hepatitis B virus (HBV) carriers worldwide, $\sim 75 \%$ of whom live in Southeast Asia and the Western Pacific regions (Ganem and Prince, 2004). The prevalence of chronic HBV infection in these endemic regions is as high as $8-15 \%$ compared with $0.3-0.5 \%$ infected individual within the USA and in the native populations of the Western hemisphere (Wands et al, 1975; Lok and McMahon, 2007).

Increasingly, HBV reactivation is described in patients with solid tumours receiving chemotherapy, particularly in breast cancer patients receiving anthracycline-based regimens (Dai et al, 2004). Hepatitis B virus reactivation appears to correlate with the level of immunosuppression of the chemotherapy administered (Liaw, 1998), as well as concomitant steroids use (Chou et al, 1992).
In 2008, the United States Centres for Disease Control and Prevention recommended HBV screening before any form of immunosuppressive therapy including cytotoxics (Weinbaum et al, 2008). However, there are still many unanswered questions with regards to $\mathrm{HBV}$ screening prior to chemotherapy for solid tumours. Particularly, convincing evidence about which appropriate population to screen, and the benefits and potential harms of antiviral therapy amongst patients who tested positive for HBV are still lacking (Hoofnagle, 2009). Importantly, universal HBV screening in patients with solid tumours may not be cost effective where prevalence of $\mathrm{HBV}$ is low (Day et al, 2011), and when chemotherapy regimens associated with low hepatitis $B$ reactivation risk are prescribed. Indeed, the American Society of Clinical Oncology issued a provisional clinical opinion in 2010 stating insufficient evidence to support routine HBV screening for all

*Correspondence: Dr S-C Lee; E-mail: csilsc@nus.edu.sg

Revised 12 April 2013; accepted 17 April 2013; published online 7 May 2013

(c) 2013 Cancer Research UK. All rights reserved 0007-0920/13 


\begin{tabular}{|c|c|c|c|c|}
\hline & $\begin{array}{c}\mathrm{AC}^{\mathrm{FAC}}{ }^{\mathrm{a}}, n=434 \\
(\%)\end{array}$ & $\begin{array}{l}\text { Folfox/Folfirib } \\
n=196(\%)\end{array}$ & $\begin{array}{l}\text { Carboplatin/Gemcitabine }{ }^{c}, \\
n=245(\%)\end{array}$ & $\begin{array}{c}\text { Capecitabine }^{\mathrm{d}}, \\
n=274(\%)\end{array}$ \\
\hline Age, years (median, range) & $52(35-75)$ & $58(26-81)$ & $58(28-79)$ & $60(28-82)$ \\
\hline \multicolumn{5}{|l|}{ Gender } \\
\hline $\begin{array}{l}\text { Male } \\
\text { Female }\end{array}$ & $\begin{array}{c}2(0.05) \\
432(99.5)\end{array}$ & $\begin{array}{c}113(58) \\
83(42)\end{array}$ & $\begin{array}{l}126(51) \\
119(49) \\
\end{array}$ & $\begin{array}{l}108(39) \\
166(61)\end{array}$ \\
\hline \multicolumn{5}{|l|}{ Race } \\
\hline $\begin{array}{l}\text { Chinese } \\
\text { Malay } \\
\text { Indian } \\
\text { Others }\end{array}$ & $\begin{array}{c}278(64) \\
74(17) \\
32(7) \\
50(12)\end{array}$ & $\begin{array}{c}163(83) \\
14(7) \\
8(4) \\
11(6)\end{array}$ & $\begin{array}{c}180(74) \\
37(15) \\
8(3) \\
20(8)\end{array}$ & $\begin{array}{c}195(71) \\
29(11) \\
11(4) \\
39(14)\end{array}$ \\
\hline \multicolumn{5}{|l|}{ Tumour type } \\
\hline $\begin{array}{l}\text { Breast } \\
\text { - Adjuvant } \\
\text { - Metastatic }\end{array}$ & $\begin{array}{c}434(100) \\
363(84) \\
71(16)\end{array}$ & $\begin{array}{l}0 \\
0 \\
0\end{array}$ & $\begin{array}{c}60(24) \\
0(0) \\
60(24)\end{array}$ & $\begin{array}{c}127(46) \\
0(0) \\
127(46)\end{array}$ \\
\hline $\begin{array}{l}\text { Colon } \\
\text { - Adjuvant } \\
\text { - Metastatic }\end{array}$ & $\begin{array}{l}0 \\
0 \\
0\end{array}$ & $\begin{array}{c}162(83) \\
76(39) \\
86(44)\end{array}$ & $\begin{array}{l}0(0) \\
0(0) \\
0(0)\end{array}$ & $\begin{array}{l}112(41) \\
71(26) \\
41(15)\end{array}$ \\
\hline Lung & 0 & $0(0)$ & $110(45)$ & $0(0)$ \\
\hline Others & 0 & $24(17)$ & $75(31)$ & $25(13)$ \\
\hline Use of steroids in pre-medication & $434(100)$ & $196(100)$ & $245(100)$ & $0(0)$ \\
\hline HBV screen & $220(51)$ & $68(35)$ & $78(32)$ & $82(30)$ \\
\hline Screen positive & $6 / 220(3)$ & 10/68 (15) & $5 / 78(7)$ & 9/82 (11) \\
\hline
\end{tabular}

cancer patients undergoing cytotoxic chemotherapy and instead recommended the exercise of 'clinical judgement' (Artz et al, 2010).

Apart from anthracyclines, the HBV reactivation risks of other commonly used chemotherapy regimens in solid tumours are not well described. We hypothesise that HBV reactivation risk differs amongs different cytotoxic regimens, and non-anthracyclinesbased chemotherapy regimens and regimens with low myelosuppression risk are associated with low risk of HBV reactivation risk.

We aim to assess and compare HBV screening rates as well as reactivation risk in patients receiving several common chemotherapy regimens for solid tumours associated with different myelosuppression risks at a tertiary cancer centre in Singapore, a developed country in Southeast Asia where HBV is endemic with a reported carrier rate of $\sim 6 \%$ (Guan, 1996), and where prior to year 2011, routine HBV screening for all patients with solid tumours undergoing chemotherapy was not universally practised.

\section{PATIENTS AND METHODS}

The medical records of eligible patients who had received one of six commonly used chemotherapy regimens for solid tumours between January 2007 and December 2010 were reviewed. The regimens were: (1) AC (doxorubicin $60 \mathrm{mg} \mathrm{m}^{-2}$, cyclophosphamide $600 \mathrm{mg} \mathrm{m}^{-2}$ ) or FAC (fluorouracil $500 \mathrm{mg} \mathrm{m}^{-2}$, doxorubicin $50 \mathrm{mg} \mathrm{m}^{-2}$, cyclophosphamide $500 \mathrm{mg} \mathrm{m}^{-2}$ every 3 weeks), (2) FolFox or Folfiri (oxaliplatin $85 \mathrm{mg} \mathrm{m}^{-2}$ or irinotecan $180 \mathrm{mg} \mathrm{m}^{-2}$ ), folinic acid $400 \mathrm{mg} \mathrm{m}^{-2}$, and bolus fluorouracil
$400 \mathrm{mg} \mathrm{m}^{-2}$ followed by infusional fluorouracil $2400 \mathrm{mg} \mathrm{m}^{-2}$ over $46 \mathrm{~h}$, every 2 weeks, (3) carboplatin (area under the concentration time curve 5), day 1 and gemcitabine $1000 \mathrm{mg} \mathrm{m}^{-2}$ days 1 and 8 , every 3 weeks, and (4) single-agent capecitabine $1000-1250 \mathrm{mg} \mathrm{m}^{-2}$ days $1-14$, every 3 weeks. These chemotherapy regimens were chosen based on their different myelosuppression risk. AC/FAC chemotherapy for breast cancers is considered high risk as it is associated with significant grade 3 and 4 neutropenia rates of 50$60 \%$, compared with $30-40 \%$ for Folfox/Folfiri and $20 \%$ for carboplatin and gemcitabine combination, which are considered moderate-risk regimens, and $<5 \%$ for capecitabine, a low-risk regimen (Tournigand et al, 2004; Twelves et al, 2005; Jones et al, 2006; Fidias et al, 2009). All patients were treated at the National University Cancer Institute, Singapore - one of two tertiary cancer centres in Singapore. Patients who started chemotherapy in 2010 but who were still actively undergoing the same regimen after June 2011 were excluded, as HBV reactivation can occur any time within 6 months upon completion of chemotherapy. Patients who were commenced on chemotherapy after December 2010 were also excluded, because from January 2011, our centre began to routinely screen all patients for HBV prior to starting cancer chemotherapy. The study was approved by the institution's ethics review board.

Definition of $\mathrm{HBV}$ screening and reactivation. Chronic HBV carriers are patients who are hepatitis B surface antigen (HBsAg)seropositive. HBV screening was defined by an HBsAg blood test within 6 months of initiation of chemotherapy. 'Hepatitis' was defined as a three-fold or more increase in serum alanine transferase (ALT) that exceeded the upper limit of the reference 
$\left(>58 \mathrm{I} \mathrm{Ul}^{-1}\right.$ ) or an absolute increase of ALT over 100I U1 ${ }^{-1}$ (Lok et al, 1991). Hepatitis attributable to HBV reactivation was defined as an increase in HBV DNA level of 10 -fold or more from the baseline level, or an absolute increase of HBV DNA level to $>10^{8} \mathrm{IU} \mathrm{ml}^{-1}$ at any time during chemotherapy and up to 6 months upon completion of chemotherapy, in the absence of other acute viral hepatitis or systemic infection (Yeo et al, 2004). Patients who were found to be HBsAg-positive on screening will undergo further serological testing for HBV including HBV DNA and hepatitis B e-antigen/antibody (HBeAg/anti-HBe) and may be started on prophylactic antiviral therapy at the discretion of the primary oncologists or the hepatologists if consulted. Prophylactic antiviral therapy was usually continued up to 6 months after chemotherapy completion with 3-monthly HBV DNA monitoring. Liver function test (LFT), which included aspartate transaminase (AST), alanine transaminase (ALT), alkaline phosphatase, total bilirubin, and albumin, was conducted 3-4-weekly during chemotherapy and at 6-12-weekly intervals upon completion of chemotherapy, where applicable. Patients who developed hepatitis with no apparent cause were investigated for viral infections including hepatitis A, B and C. All patients who developed hepatitis due to HBV reactivation were referred to and treated by hepatologists. Disruption of chemotherapy treatment was defined as premature termination of treatment or delay of $>8$ days (Yeo et al, 2004).

\section{RESULTS}

A total of 1149 patients were reviewed (Table 1), including 434 (38\%) who received anthracycline-based chemotherapy (AC/FAC), 196 (17\%) who received oxaliplatin- or irinotecan-based combinations (Folfox/Folfiri), 245 (21\%) who received carboplatin/ gemcitabine, and 274 (24\%) who received single-agent capecitabine. Median age of the whole cohort was 57 years (range 26-82). Seventy per cent of the patients were female, as more than half (621 out of $1149,54 \%$ ) of our studied population were breast cancer patients, of which 59\% received adjuvant treatment with AC/FAC. Overall, HBV screening rate was 39\%, but was highest for AC/FAC (51\%) compared with the other three regimens (35\% for Folfox/ Folfiri, 32\% for carboplatin/gemcitabine, and 30\% for single-agent capecitabine, $P<0.001)$. Except for single-agent capecitabine, all patients treated with the other three regimens received steroids pre-medication with intravenous dexamethasone $8-16 \mathrm{mg}$ bolus before each cycle of chemotherapy. In addition, patients who were treated with AC/FAC or Folfox/Folfiri regimens also routinely received oral dexamethasone $4-8 \mathrm{mg}$ per day for 2-3 days as an anti-emetic after each cycle of chemotherapy.

Of the 448 patients who were screened for hepatitis B, 30 (7\%) were found to be HBsAg-positive. Of these, 28 received prophylactic antiviral therapy (24 received lamivudine (AC/FAC - 6, Capecitabine - 8, Folfox/Folfiri - 6, and Carboplatin/Gemcitabine - 4, respectively), while 4 had entecavir (Capecitabine - 1, and Folfox/ Folfiri - 3) and none had HBV reactivation. The mean baseline HBV DNA level for these 30 patients was $1.46 \pm 5.77 \times 10^{7} \mathrm{IU} \mathrm{ml}^{-1}$ (range undetectable $(<200)$ to $2.8 \times 10^{8} \mathrm{IU} \mathrm{ml}^{-1}$ ). Two HBsAgpositive patients who received carboplatin/gemcitabine and Folfox regimens, respectively, were not prescribed prophylactic antiviral therapy, and both did not have HBV reactivation.

Amongst the unscreened population in our study, 77 out of 701 (11\%) were noted to have transaminitis that fulfilled the definition of hepatitis during or within 6 months of completing chemotherapy. Of these, 9 out of 77 patients were subsequently screened for hepatitis B; 6 patients were HBsAg-negative, while 3 patients were HBsAgpositive with elevated HBV DNA and were diagnosed with acute hepatitis B flare. All three patients received anthracyclines-containing chemotherapy. Of the remaining 68 patients who had transaminitis and/or deranged liver function without HBsAg screen, 60 were patients with advanced disease with liver metastasis and documented progression, 3 patients had documented systemic infection that accounted for the laboratory abnormalities, while the remaining 5 patients had $\leqslant$ grade 2 transaminitis that resolved within 3-4 weeks without treatment and hospitalisation, and that did not recur with subsequent chemotherapy cycles. Of these five patients, three received $\mathrm{AC} / \mathrm{FAC}$, one received capecitabine and one was treated with carboplatin/gemcitabine.

Overall, 3 out of the 1149 patients (0.3\%) developed documented HBV reactivation. All 3 were breast cancer patients from the unscreened doxorubicin group ( 3 out of 214 , reactivation rate $1.4 \%)$ compared with 0 out of $487(0 \%)$ unscreened patients in the other three groups $(P<0.001)$. All three patients were admitted for acute hepatitis and had HBV DNA levels $>10^{8} \mathrm{IU} \mathrm{ml}^{-1}$ at the time of admission. One patient with metastatic breast cancer died of fulminant liver failure despite antiviral treatment. The other two patients recovered but had significant delays in their cancer therapy due to $\mathrm{HBV}$ reactivation. Among the unscreened patient group, $\mathrm{HBV}$ reactivation rate was $0.4 \%$ (3 out of 701 ).

\section{DISCUSSION}

While $\mathrm{HBV}$ reactivation is a recognised complication in patients with solid tumours undergoing cytotoxic therapy, there is still much to know about the exact frequency of HBV reactivation and its associated risk factors. Our study showed that the overall clinically apparent HBV reactivation risk in patients with solid tumours treated with chemotherapy is low (0.3\% (3 out of 1149 overall), $0.4 \%$ (3 out of 701 unscreened patients)) even in an endemic region. In particular, none of the 487 unscreened patients who were treated with oxaliplatin- or irinotecan-based chemotherapy, gemcitabine/carboplatin, or single-agent capecitabine developed clinically evident $\mathrm{HBV}$ reactivation. However, while the overall $\mathrm{HBV}$ reactivation risk in cancer patients undergoing chemotherapy is low, $\mathrm{HBV}$ reactivation remains an important cause of hepatitis outside of progressive liver disease and systemic infections, accounting for 3 out of 9 patients (33\%) who developed hepatitis and who were eventually screened for HBV infection. Notably, all three patients were treated with anthracyclinescontaining chemotherapy.

Several risk factors for HBV reactivation in cancer patients have been identified, such as treatment for haematologic malignancies, types of immunosuppressant agents and high level of prechemotherapy HBV DNA, though the mechanism and magnitude of risk remain ill understood (Zhong et al, 2004). Among the chemotherapeutic agents, anthracyclines and corticosteroids are most frequently implicated. Anthracyclines have been shown in vitro to stimulate HBV DNA secretion, while glucocorticoid steroids bind to the glucocorticoid-responsive element on the HBV DNA, which facilitates viral replication (Tur-Kaspa et al, 1986; Hsu et al, 2004). In our study, all three cases of HBV reactivation occurred in breast cancers patients receiving anthracycline-based chemotherapy. Strikingly, there were no HBV reactivation amongst patients in the other three non-anthracyclines regimen groups despite similar usage of glucocorticoids pre-medication therapy (with the exception of single-agent capecitabine, which was not usually co-administered with steroids) and lower screening rates, underscoring the fact that universal screening and prescription of prophylactic antiviral therapy in cancer patients receiving 'low- or moderate-risk' chemotherapy regimens may not be cost effective even in an endemic region.

In other HBV-endemic regions such as Hong Kong and Korea, several prospective studies of breast cancer patients receiving 
anthracycline-based chemotherapy have reported clinically significant HBV reactivation rate to be around $20-25 \%$ in HBsAgpositive patients who did not receive prophylactic antiviral therapy (Yeo et al, 2003; Kim et al, 2007). Our study showed comparable results. Assuming a HBsAg-positive rate of $6 \%$ in our population, we would expect $\sim 12$ patients from the 214 unscreened patients who received anthracycline-based chemotherapy to be $\mathrm{HBsAg}$ positive. Of these, 3 patients developed acute hepatitis secondary to $\mathrm{HBV}$ reactivation, yielding an estimated $25 \%$ (three out of 12) reactivation rate among $\mathrm{HBsAg}$-positive patients, which is consistent with previous reports. Our study thus supports routine hepatitis B screening in patients receiving 'high-risk' anthracyclines-containing chemotherapy followed by prophylactic antiviral therapy in HBsAg-positive patients, as HBV reactivation rate is high with significant mortality and prophylaxis is effective, as shown by our study and others (Loomba et al, 2008; Yun et al, 2011). If not previously determined, HBsAg status should be checked prior to starting any anthracycline-based chemotherapy regardless of the line of treatment.

However, universal HBV screening may not be cost effective in our population based on simple calculations, taking into consideration costs associated with HBV screening and management of $\mathrm{HBV}$-positive patients. With a $\mathrm{HBV}$ reactivation rate of $0.4 \%$ amongst the unscreened population group as shown in our study, the numbers needed to screen to prevent $1 \mathrm{HBV}$ flare is 250 patients. Of these 250 patients who are screened, $\sim 15$ patients will be HBsAg-positive given our $\mathrm{HBV}$ carrier rate of $\sim 6 \%$ in Singapore, and will go on to receive prophylactic antiviral therapy such as lamivudine, entecavir, and so on. The cost of screening 250 patients with only HBsAg is $\sim \$ \$ 5250$ (estimated cost at $\$ \$ 21$ per test), while the cost of treating $15 \mathrm{HBsAg}$-positive patients with suppressive antiviral therapy during chemotherapy and for an additional 6 months thereafter (estimated cost of $S \$ 160$ per month for 12 months per patient $\times 15$ patients), with follow-up blood tests including HBV DNA titres and consultation charges with hepatologists (estimated cost of S\$200 every 3 months $\times 4 \times 15$ patients) is $\sim \$ \$ 40000$. These are substantial costs for low-risk chemotherapy regimens such as oral capecitabine, which did not result in acute hepatitis $B$ reactivation in our study. In comparison, the cost of treating one patient who is hospitalised for a median duration of 11 days for acute hepatitis $B$ reactivation is estimated to be $S \$ 3500$ (Kim et al, 2007). While this analysis does not take into account potential mortality from acute hepatitis B flare or morbidities from prophylactic antiviral therapy such as adverse drug reactions and long-term drug resistance issue, and so on, it does suggest that universal hepatitis B screening may not be cost effective for certain low-risk chemotherapy regimens.

Limitations. Given the retrospective nature of this study, we were unable to provide objective data on factors that influenced physicians' decisions to screen or not screen certain patients. Also, in comparing $\mathrm{HBV}$ reactivation rates amongst the various chemotherapy regimens, we have assumed that the HBV carrier rate is approximately the same amongst the patient groups, though this may not necessarily be so. Only 6 out of 220 (3\%) of breast cancer patients receiving anthracyclines-containing combinations were screened positive for $\mathrm{HBsAg}$ compared with 10 out of 68 (15\%) for patients receiving irinotecan or oxaliplatin-containing chemotherapy and 9 out of $82(11 \%)$ for carboplatin/gemcitabine combination. These differences are in part due to small sample sizes in the different subgroups, as well as possibly reflecting differences in patients' demographics as the latter two groups have a higher proportion of Chinese patients who have reportedly the highest HBV carrier rates amongst the different ethnics groups in Singapore (Guan, 1996).

In addition, HBV reactivation may have been under-diagnosed, as an estimated $15 \%$ patients may have asymptomatic HBV reactivation without clinical evidence of hepatitis when routine HBV DNA was monitored at 2-3-weekly intervals (Yeo et al, 2003). Serial HBV DNA monitoring in patients receiving chemotherapy is, however, not widely practised outside the setting of clinical trials, and is not routinely done in our institution, although we regularly monitor liver function tests every 3-4 weeks during chemotherapy and every 6-12 weeks after chemotherapy where applicable, and should identify most cases of hepatitis. Another limitation is that HBV was not tested for all patients who subsequently developed hepatitis, as a large majority (60 out of 77; $78 \%$ ) had advanced cancer to the liver, which was presumed to be the cause of the hepatitis, and thus further investigations were not performed to rule out infective causes. Some of these patients may have co-existing HBV reactivation as the cause of the hepatitis, resulting in underestimation of the $\mathrm{HBV}$ reactivation rate in this study, although we believe that the number of undiagnosed cases is small and would not have altered the results of this study substantially.

\section{CONCLUSION}

Not all chemotherapy regimens are associated with the risk of HBV reactivation. While routine $\mathrm{HBV}$ screening for patients with solid tumours on high-dose glucocorticoids or high-risk anthracyclinescontaining regimens is supported, routine screening and antiviral prophylaxis for other lower-risk chemotherapy regimens, such as single-agent capecitabine, oxaliplatin- or irinotecan-based chemotherapy, or gemcitabine/carboplatin, may not be necessary even in endemic regions like Singapore. Ideally, these findings should be further evaluated and confirmed by prospective studies. Nevertheless, our study highlights the need to re-evaluate the current HBV screening guidelines for cancer patients undergoing immunosuppressive therapy.

\section{ACKNOWLEDGEMENTS}

We thank Mr Hing Wee Chuan and the Department of Pharmacy, National University Health System, Singapore, for their kind assistance in retrieving patients' records for this study.

\section{CONFLICT OF INTEREST}

The authors declare no conflict of interest.

\section{REFERENCES}

Artz AS, Somerfield MR, Feld JJ, Giusti AF, Kramer BS, Sabichi AL, Zon RT, Wong SL (2010) American Society of Clinical Oncology provisional clinical opinion: chronic hepatitis B virus infection screening in patients receiving cytotoxic chemotherapy for treatment of malignant diseases. $J$ Clin Oncol 28: 3199-3202.

Chou CK, Wang LH, Lin HM, Chi CW (1992) Glucocorticoid stimulates hepatitis B viral gene expression in cultured human hepatoma cells. Hepatology 16: 13-18.

Dai MS, Wu PF, Shyu RY, Lu JJ, Chao TY (2004) Hepatitis B virus reactivation in breast cancer patients undergoing cytotoxic chemotherapy and the role of preemptive lamivudine administration. Liver Int 24: 540-546.

Day FL, Karnon J, Rischin D (2011) Cost-effectiveness of universal hepatitis B virus screening in patients beginning chemotherapy for solid tumors. J Clin Oncol 29: 3270-3277.

Fidias PM, Dakhil SR, Lyss AP, Loesch DM, Waterhouse DM, Bromund JL, Chen R, Hristova-Kazmierski M, Treat J, Obasaju CK, Marciniak M, Gill J, Schiller JH (2009) Phase III study of immediate compared with delayed 
docetaxel after front-line therapy with gemcitabine plus carboplatin in advanced non-small-cell lung cancer. J Clin Oncol 27: 591-598.

Ganem D, Prince AM (2004) Hepatitis B virus infection - natural history and clinical consequences. N Engl J Med 350: 1118-1129.

Guan R (1996) Hepatitis B virus infection in Singapore. Gut 38(Suppl 2): S13-S17.

Hoofnagle JH (2009) Reactivation of Hepatitis B. Hepatology 49: S156-S165.

Hsu CH, Hsu HC, Chen HL, Gao M, Yeh PY, Chen PJ, Cheng AL (2004) Doxorubicin activates hepatitis B virus (HBV) replication in HBVharboring hepatoblastoma cells. A possible novel mechanism of HBV reactivation in HBV carriers receiving systemic chemotherapy. Anticancer Res 24: 3035-3040.

Jones SE, Savin MA, Holmes FA, O'Shaughnessy JA, Blum JL, Vukelja S, McIntyre KJ, Pippen JE, Bordelon JH, Kirby R, Sandbach J, Hyman WJ, Khandelwal P, Negron AG, Richards DA, Anthony SP, Mennel RG, Boehm KA, Meyer WG, Asmar L (2006) Phase III trial comparing doxorubicin plus cyclophosphamide with docetaxel plus cyclophosphamide as adjuvant therapy for operable breast cancer. J Clin Oncol 24: 5381-5387.

Kim MK, Ahn JH, Kim SB, Im YS, Lee SI, Ahn SH, Son BH, Gong G, Kim HH, Kim WK (2007) Hepatitis B reactivation during adjuvant anthracycline-based chemotherapy in patients with breast cancer: a single institution's experience. Korean J Intern Med 22: 237-243.

Liaw YF (1998) Hepatitis viruses under immunosuppressive agents. $J$ Gastroenterol Hepatol 13: 14-20.

Lok AS, Liang RH, Chiu EK, Wong KL, Chan TK, Todd D (1991) Reactivation of hepatitis B virus replication in patients receiving cytotoxic therapy. Report of a prospective study. Gastroenterology 100: 182-188.

Lok AS, McMahon BJ (2007) Chronic hepatitis B. Hepatology 45: 507-539.

Loomba R, Rowley A, Wesley R, Liang TJ, Hoofnagle JH, Pucino F, Csako G (2008) Systematic review: the effect of preventive lamivudine on hepatitis $\mathrm{B}$ reactivation during chemotherapy. Ann Intern Med 148: 519-528.

Tournigand C, Andre T, Achille E, Lledo G, Flesh M, Mery-Mignard D, Quinaux E, Couteau C, Buyse M, Ganem G, Landi B, Colin P, Louvet C, de Gramont A (2004) FOLFIRI followed by FOLFOX6 or the reverse sequence in advanced colorectal cancer: a randomized GERCOR study. $J$ Clin Oncol 22: 229-237.

Tur-Kaspa R, Burk RD, Shaul Y, Shafritz DA (1986) Hepatitis B virus DNA contains a glucocorticoid-responsive element. Proc Natl Acad Sci USA 83: $1627-1631$.

Twelves C, Wong A, Nowacki MP, Abt M, Burris 3rd H, Carrato A, Cassidy J, Cervantes A, Fagerberg J, Georgoulias V, Husseini F, Jodrell D, Koralewski P, Kroning H, Maroun J, Marschner N, McKendrick J, Pawlicki M, Rosso R, Schuller J, Seitz JF, Stabuc B, Tujakowski J, Van Hazel G, Zaluski J, Scheithauer W (2005) Capecitabine as adjuvant treatment for stage III colon cancer. N Engl J Med 352: 2696-2704.

Wands JR, Chura CM, Roll FJ, Maddrey WC (1975) Serial studies of hepatitisassociated antigen and antibody in patients receiving antitumor chemotherapy for myeloproliferative and lymphoproliferative disorders. Gastroenterology 68: 105-112.

Weinbaum CM, Williams I, Mast EE, Wang SA, Finelli L, Wasley A, Neitzel SM, Ward JW (2008) Recommendations for identification and public health management of persons with chronic hepatitis B virus infection. MMWR Recomm Rep 57: 1-20.

Yeo W, Chan PK, Hui P, Ho WM, Lam KC, Kwan WH, Zhong S, Johnson PJ (2003) Hepatitis B virus reactivation in breast cancer patients receiving cytotoxic chemotherapy: a prospective study. J Med Virol 70: 553-561.

Yeo W, Zee B, Zhong S, Chan PK, Wong WL, Ho WM, Lam KC, Johnson PJ (2004) Comprehensive analysis of risk factors associating with Hepatitis B virus (HBV) reactivation in cancer patients undergoing cytotoxic chemotherapy. Br J Cancer 90: 1306-1311.

Yun J, Kim KH, Kang ES, Gwak GY, Choi MS, Lee JE, Nam SJ, Yang JH, Park YH, Ahn JS, Im YH (2011) Prophylactic use of lamivudine for hepatitis B exacerbation in post-operative breast cancer patients receiving anthracycline-based adjuvant chemotherapy. Br J Cancer 104: 559-563.

Zhong S, Yeo W, Schroder C, Chan PK, Wong WL, Ho WM, Mo F, Zee B, Johnson PJ (2004) High hepatitis B virus (HBV) DNA viral load is an important risk factor for HBV reactivation in breast cancer patients undergoing cytotoxic chemotherapy. J Viral Hepat 11: 55-59. 